\title{
Bioleaching of gold, copper and nickel from waste cellular phone PCBs and computer goldfinger motherboards by two Aspergillus niger strains
}

\author{
Jorge Enrique Madrigal-Arias ${ }^{1}$, Rosalba Argumedo-Delira ${ }^{2}$, Alejandro Alarcón ${ }^{4}$, \\ Ma. Remedios Mendoza-López², Oscar García-Barradas², Jesús Samuel Cruz-Sánchez², \\ Ronald Ferrera-Cerrato ${ }^{4}$, Maribel Jiménez-Fernández ${ }^{3}$ \\ ${ }^{1}$ Facultad de Ingeniería y Ciencias Químicas, Universidad Veracruzana, Veracruz, México. \\ ${ }^{2}$ Unidad de Servicios de Apoyo en Resolución Analítica, Universidad Veracruzana, Veracruz, México. \\ ${ }^{3}$ Instituto de Ciencias Básicas, Universidad Veracruzana, Veracruz, México. \\ ${ }^{4}$ Área de Microbiología, Postgrado de Edafología, Colegio de Postgraduados, Estado de México, México.
}

Submitted: March 26, 2014; Approved: December 28, 2014.

\begin{abstract}
In an effort to develop alternate techniques to recover metals from waste electrical and electronic equipment (WEEE), this research evaluated the bioleaching efficiency of gold $(\mathrm{Au})$, copper $(\mathrm{Cu})$ and nickel (Ni) by two strains of Aspergillus niger in the presence of gold-plated finger integrated circuits found in computer motherboards (GFICMs) and cellular phone printed circuit boards (PCBs). These three metals were analyzed for their commercial value and their diverse applications in the industry. Au-bioleaching ranged from 42 to 1\% for Aspergillus niger strain MXPE6; with the combination of Aspergillus niger MXPE6 + Aspergillus niger MX7, the Au-bioleaching was 87 and $28 \%$ for PCBs and GFICMs, respectively. In contrast, the bioleaching of $\mathrm{Cu}$ by Aspergillus niger MXPE6 was 24 and 5\%; using the combination of both strains, the values were 0.2 and $29 \%$ for PCBs and GFICMs, respectively. Fungal Ni-leaching was only found for PCBs, but with no significant differences among treatments. Improvement of the metal recovery efficiency by means of fungal metabolism is also discussed.
\end{abstract}

Key words: bioleaching, PCBs, Aspergillus, gold, WEEE.

\section{Introduction}

The use of electrical and electronic equipment (EEE) has significantly increased in recent decades throughout the world, generating large amounts of waste electrical and electronic equipment (WEEE) (He et al., 2006; GavilánGarcía et al., 2009). WEEE contains toxic components such as $\mathrm{Pb}, \mathrm{Cd}, \mathrm{Hg}, \mathrm{Cr} \mathrm{VI}$, and polybrominated biphenyls but also valuable materials such as plastic, $\mathrm{Fe}, \mathrm{Cu}, \mathrm{Al}, \mathrm{Au}$, Ag, Pd, and other metals (Sum, 1991; Sodhi et al., 2001; Huang et al., 2009). Among WEEE, the gold-plated finger integrated circuits found in computer motherboards (GFICMs) and the printed circuit boards of cellular phones (PCBs) are a rich secondary source of metals such as $\mathrm{Cu}$, $\mathrm{Au}, \mathrm{Pd}$ and $\mathrm{Ag}$ (Lee et al., 2007). Their recovery is typically achieved by pyrometallurgical and hydrometallurgical pro- cesses, which have certain energy and environmental disadvantages (Cui and Zhang, 2008; Weidenhamer and Clement, 2007). Therefore, some microbiological processes have been proposed as alternatives to chemical processes for treating such electronic waste. For instance, bacteria such as Thiobacillus ferrooxidans and T. thiooxidans and fungi such as Aspergillus niger and Penicillium simplicissimum are able to mobilize high percentages of $\mathrm{Cu}, \mathrm{Sn}, \mathrm{Al}, \mathrm{Ni}, \mathrm{Pb}$ and $\mathrm{Zn}$ powder from WEEE (Brandl et al., 2001). In addition, Chromobacterium violaceum may solubilize $\mathrm{Au}$ and $\mathrm{Cu}$ as dicyanoaurate and dicyanocuprate $\left(\left[\mathrm{Au}(\mathrm{CN})_{2}\right]\right.$ and $\left[\mathrm{Cu}(\mathrm{CN})_{2}\right]$, respectively) from manually cut PCBs under in vitro systems (Brandl and Faramarzi, 2006). Acidithiobacillus ferrooxidans is also capable to solubilize copper from PCBs; moreover, the $\mathrm{Cu}$ concentra-

Send correspondence to R. Argumedo-Delira. Unidad de Servicios de Apoyo en Resolución Analítica, Universidad Veracruzana. Luis Castelazo Ayala s/n, Col. Industrial Animas, 91190, Xalapa, Veracruz, México. E-mail: rargumedo@uv.mx. 
tion in the solution is significantly increased by an Feenriched culture medium (Choi et al., 2004). Pham and Ting (2009) showed that applying a bio-oxidation pretreatment with $A$. ferrooxidans to electronic wastes resulted in improved Cu-removal (80\% in average), with Au-bioleaching/recovering being achieved by $C$. violaceum inoculation. In addition, Chi et al. (2011) reported that $C$. violaceum increases $\mathrm{Au}$ and $\mathrm{Cu}$ leaching from the PCBs of cellular phones from $7.78 \%$ to $10.8 \%$ and from $4.9 \%$ to $11.4 \%$, respectively, during 8 days of incubation. In contrast, knowledge of metal bioleaching from WEEE by filamentous fungi is still scarce. Therefore, this study evaluated the tolerance to gold of four strains of Aspergillus and the bioleaching efficiency of gold, copper and nickel from PCBs and GFICMs by Aspergillus strains with higher tolerance to gold.

\section{Materials and Methods}

\section{Fungal isolates}

Aspergillus niger MX7 and Aspergillus sp. MX9 were isolated from metal-contaminated soil around a landfill located at Tronconal, Xalapa, Veracruz, Mexico. Aspergillus niger MXPE6 and Aspergillus sp. MXPE8 were isolated from an electronic board found at the same location.

\section{Tolerance of Aspergillus strains to gold}

The fungal strains were grown in Petri dishes containing potato dextrose agar (PDA, Baker ${ }^{\circ}$ ) at $28{ }^{\circ} \mathrm{C}$ for 5 days. Afterwards, individual PDA disks ( $7 \mathrm{~mm}$ diameter) with each fungal strain were extracted and placed on new Petri dishes with PDA. Gold was supplied in the culture medium by the addition of $\left(\mathrm{AuCl}_{3}\right.$, Sigma-Aldrich $\left.{ }^{\circledR}\right) 50$, 150 or $300 \mathrm{mg} \mathrm{L}^{-1}$ at $\mathrm{pH}$ 4.0. The Petri dishes were incubated at $28 \pm 2{ }^{\circ} \mathrm{C}$ for 11 days, and the fungal growth was assessed by measuring the diameter of each fungal colony every $24 \mathrm{~h}$. Petri dishes without gold were used as controls.

\section{Dismantling and downsizing of PCBs and GFICMs}

Cellular phones were dismantled, and the metal parts were separated from the plastic components to obtain PCBs, which were hand-cut to a size of approximately $1 \times 1$ $\mathrm{cm}(\sim 200 \mathrm{mg}$ in weight). In the case of GFICMs, the samples were cut to a size of $0.850 \mathrm{~mm}$. Both materials were washed with a solution of $1 \% \mathrm{NaClO}$ and five rinses with ethanol. Subsequently, $200 \mathrm{mg}$ of each material were separately digested with aqua regia for $8 \mathrm{~h}$, and the dissolved samples were analyzed using an ICP optical emission spectrometer (Varian ${ }^{\circledR}$ Model 725-725-ES) to determine the contents of $\mathrm{Au}, \mathrm{Cu}$ and $\mathrm{Ni}$. This research focused on analyzing $\mathrm{Au}, \mathrm{Cu}$ and $\mathrm{Ni}$ due to their commercial value and diverse applications in industries such as electricity, electronics, chemical, aerospace, and automotive. Additionally, these metals are the main components in electronic wastes (Richardson, 1997; Corti and Holliday, 2004; Osorio-Hernández, 2009; Tuncuk et al., 2012).

\section{Bioleaching culture conditions}

Aspergillus strains with a high tolerance to gold were grown in Petri dishes with potato dextrose agar (PDA, Merck $^{\circledR}$ ) at $28^{\circ} \mathrm{C}$ for 5 days; agar disks with fungal mycelium ( $7 \mathrm{~mm}$ diameter) were then used as inoculum for each fungal strain. A $15 \mathrm{~mL}$ aliquot of mineral liquid medium (g L L $; 0.1 \quad \mathrm{CaCl}_{2}, \quad 0.5 \quad \mathrm{KH}_{2} \mathrm{PO}_{4}, \quad 1.5 \quad \mathrm{NH}_{4} \mathrm{Cl}, 0.025$ $\mathrm{MgSO}_{4} .7 \mathrm{H}_{2} \mathrm{O}, 50$ glucose, $\mathrm{pH} 4.4$ ) was added to $50 \mathrm{~mL}$ vials, and $200 \mathrm{mg}$ of the previously washed and dried materials of PCBs or GFICMs was added. After that, a single PDA disk of fungal mycelium $(\sim 0.0017 \mathrm{~g}$ fungal dry weight) was added, and the treatments were incubated at 28 $\pm 2{ }^{\circ} \mathrm{C}$ at $280 \mathrm{rpm}$ for 14 days. Previous experiments showed that the single inoculation of $A$. niger MX7 did not exert significant effects on the bioleaching of gold (Madrigal-Arias unpublished data). Thus, this fungal strain was only assessed in combination with A. niger MXPE6.

\section{Determining the bioleaching ability, $\mathrm{pH}$ and fungal biomass}

After incubation, fungal mycelium was separated from the culture medium by vacuum filtration and dried at $45^{\circ} \mathrm{C}$ for $48 \mathrm{~h}$ to determine the fungal dry weight. The filtered culture medium was analyzed for measuring the $\mathrm{pH}$ and for quantifying the content of dissolved $\mathrm{Au}, \mathrm{Cu}$ and $\mathrm{Ni}$ using an ICP optical emission spectrometer $\left(\operatorname{Varian}^{\circledR}\right.$ Model 725-ES).

\section{Statistical analysis}

To assess the fungal tolerance to gold, a $4 \times 3$ factorial experiment was set up in a completely randomized experimental design (four Aspergillus strains and three metal doses). The bioleaching assay was established using a $2 \times 2$ factorial experiment in a completely randomized design, including two levels of fungal strains and two levels of materials. Each treatment for each assay had three replicates. The data were analyzed using an analysis of variance and a mean comparison test (Tukey, $\alpha=0.05$ ) using the SAS statistical program (SAS Institute, 2010).

\section{Results and Discussion}

\section{Tolerance of Aspergillus strains to gold}

The presence of $50 \mathrm{mg} \mathrm{Au} \mathrm{L}^{-1}$ did not significantly $(p<0.001)$ inhibit the growth of any of the four species of Aspergillus, for all sampling times (Figure 1 and Figure 2). However, the doses of $150 \mathrm{mg} \mathrm{Au} \mathrm{L}^{-1}$ and $300 \mathrm{mg} \mathrm{Au} \mathrm{L}^{-1}$ caused growth inhibition of Aspergillus sp. MX9 and Aspergillus sp. MXPE8 (Figures 2c, 2d). Overall, A. niger showed a high tolerance to doses of $150 \mathrm{mg} \mathrm{L}^{-1}$ and $300 \mathrm{mg}$ $\mathrm{L}^{-1}$, and $A$. niger MXPE6 was more tolerant to Au than $A$. niger MX7 (Figures 2a, 2b). 
Furthermore, some studies have found that the presence of trace amounts of $\mathrm{Au}^{0}$ and $\mathrm{Au}^{3+}$ ions does not affect the growth of microorganisms because $\mathrm{Au}$ ions are often deposited in cell walls and periplasmic membranes (Biryuzova et al., 1987). This could explain why some of the Aspergillus strains showed no significant growth inhibition at a dose of $50 \mathrm{mg} \mathrm{Au} \mathrm{L}^{-1}$. Additionally, the Au tolerance observed for the four species of Aspergillus was higher than that reported by Karamushka and Gadd (1999) for Saccharomyces cerevisiae, whose growth was inhibited at doses of $39.4 \mathrm{mg} \mathrm{Au} \mathrm{L}{ }^{-1}$.

\section{Content of gold, copper and nickel from samples of PCBs and GFICMs and recovery through fungal bioleaching}

The GFICMs and PCBs samples analyzed by ICP optical emission spectrometry showed that the contents of dissolved $\mathrm{Au}$ and $\mathrm{Cu}$ were greater from the GFICMs than the PCBs materials (Table 1). In contrast, the content of dissolved nickel was similar for both materials.

In the case of induced Au-bioleaching due to fungal activity, significant differences $(\mathrm{p} \leq 0.001)$ were observed between the fungal strains. The Au-bioleaching from PCBs materials with the consortium of both Aspergillus strains doubled the amount of $\mathrm{Au}$ in the culture medium when compared to the single inoculation of A. niger MXPE6 (Figure 3a). Thus, the recovery of Au from PCBs samples was $87 \%$ for the combination of the two Aspergillus strains, whereas the recovery for $A$. niger strain MXPE6 was $42 \%$ (Figure 3a). In the case of GFICMs, the amount of Au-bioleaching was 28 times greater with the combination of both Aspergillus strains than that obtained with only A. niger MXPE6 (Figure 3b).

There were significant differences $(\mathrm{p} \leq 0.001)$ in the ability of the fungi to induce $\mathrm{Cu}$-leaching from the PCBs and GFICMs materials. Figures $3 \mathrm{c}-\mathrm{d}$ show that the amount of $\mathrm{Cu}$-leaching was higher from PCBs than GFICMs, and the recovery of $\mathrm{Cu}$ from $\mathrm{PCBs}$ was greater with the single inoculation of $A$. niger MXPE6 (5\%) when compared to the combination of both Aspergillus strains ( $0.2 \%$ ) (Figure 3c).

In contrast, the recovery of $\mathrm{Cu}$ from GFICMs was $26 \%$ in average in both fungal treatments but was greater with the combination of both Aspergillus strains (29\%) in comparison to A. niger MXPE6 (24\%). No significant differences were found for Ni-bioleaching; moreover, fungi showed limited ability to dissolve this metal, especially from the PCBs material. Thus, the recovery of Ni in the culture medium with the combination of both Aspergillus strains was $0.6 \%$, while for $A$. niger MXPE6 inoculation this recovery was $0.8 \%$.

Results indicate that by using a fungal consortium, the recovery of Au from GFICMs or PCBs is significantly increased when compared to the single fungal inoculation. However, comparisons of our results were not possible because scientific information about Au-bioleaching from PCBs and GFICMs materials using filamentous fungi is still lacking.

Some organic acids such as citric acid produced by $A$. niger may cause the leaching of $\mathrm{Cu}, \mathrm{Cd}, \mathrm{Zn}, \mathrm{Mn}, \mathrm{Pb}, \mathrm{Cr}$ and $\mathrm{Al}$ from red mud and ashes derived from the incineration of municipal waste (Singer et al., 1982; Vachon et al., 1994; Bosshard et al., 1996). Similarly, A. niger is also capable of leaching $\mathrm{Cu}(60 \%)$ from mine waste, and $\mathrm{Cu}(68 \%), \mathrm{Zn}$ (46\%) and $\mathrm{Ni}(34 \%)$ from low-grade oxide ores (Mulligan et al., 1999; Mulligan and Kamali, 2003; Mulligan et al., 2004).

Nonetheless, studies on the leaching of $\mathrm{Cu}$ and $\mathrm{Ni}$ from WEEE by $A$. niger or other filamentous fungi are scarce. Brandl et al. (2001) reported that Aspergillus niger is able to recover $41 \%\left(80,000 \mathrm{mg} \mathrm{L}^{-1}\right)$ of $\mathrm{Cu}$ and $80 \%$ $\left(15,000 \mathrm{mg} \mathrm{L}^{-1}\right)$ of Ni from WEEE powder. These results are in agreement with our findings for $\mathrm{Cu}$ - and Ni-bioleaching but also suggest that fungal bioleaching ability may depend on the type of material, particle size, and fungal growth condition.

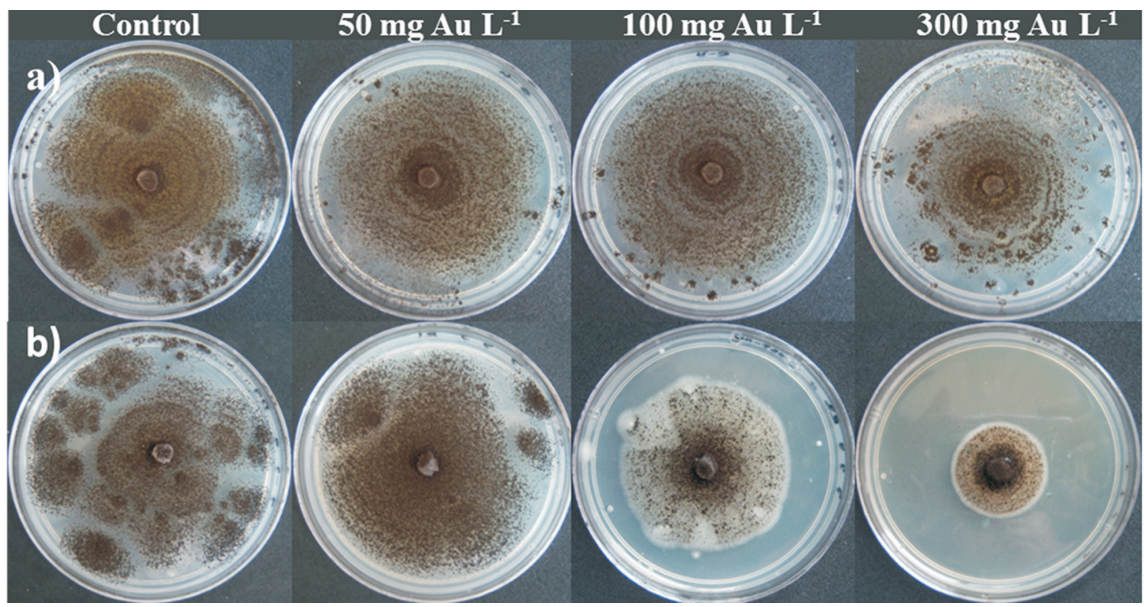

Figure 1 - Growth response of two A. niger strains exposed to four doses of $\mathrm{AuCl}_{3}\left(\mathrm{mg} \mathrm{L}^{-1}\right)$ for 11 days. a) A. niger MXPE6 and b) A. niger MX7. 

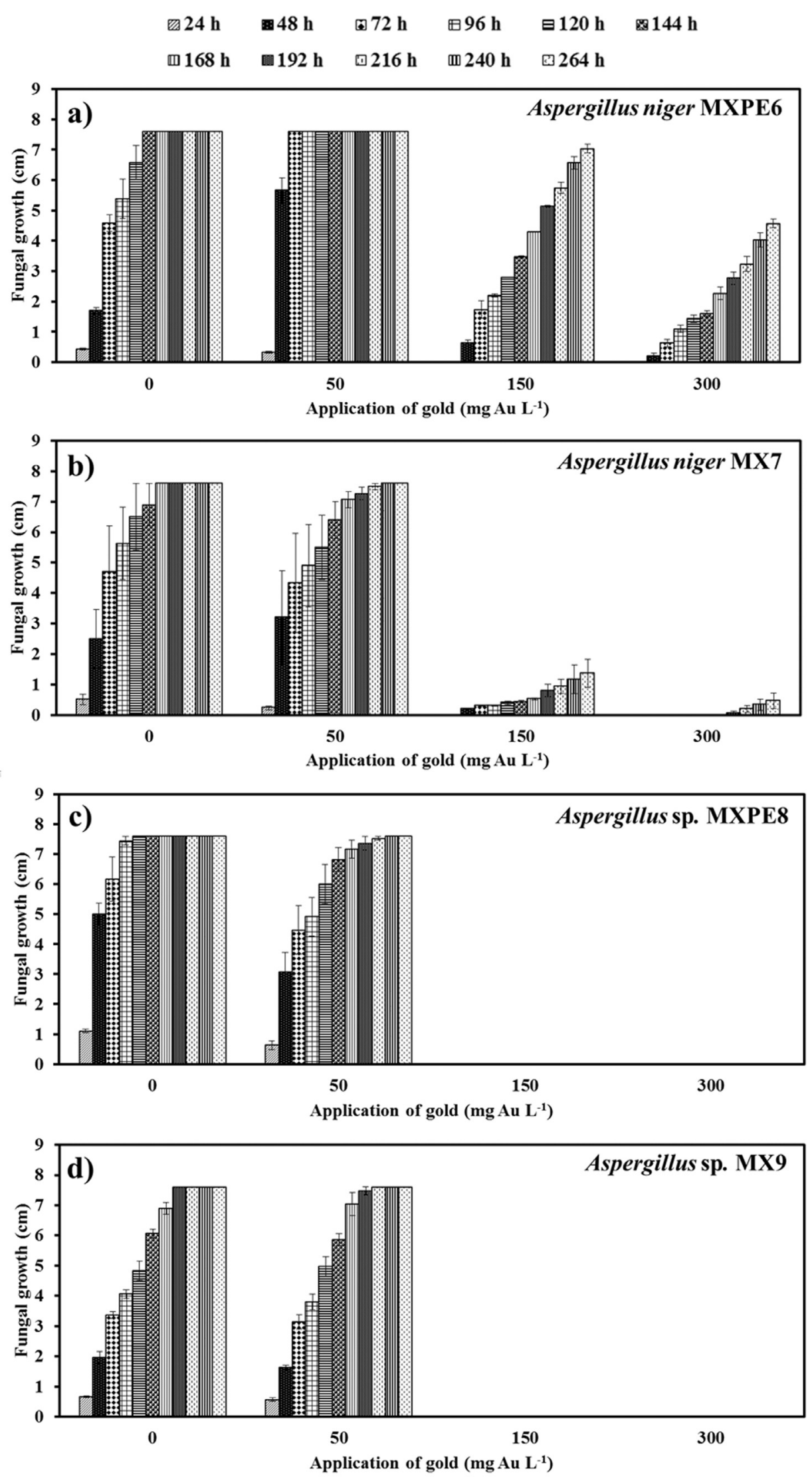

Figure 2 - Growth response of four Aspergillus strains exposed to four doses of $\mathrm{AuCl}_{3}\left(\mathrm{mg} \mathrm{L}^{-1}\right)$ for 11 days. a-b) Fungal growth of $A$. niger $\mathrm{MXPE6}$ and $A$. niger MX7; c-d) fungal growth of Aspergillus sp. MXPE8 and Aspergillus sp. MX9. 
Table 1 - Content of gold ( $\mathrm{Au})$, copper $(\mathrm{Cu})$ and nickel (Ni) from samples of printed circuit boards of celullar phones (PCBs) and the gold-plated finger integrated circuits found in computer motherboards (GFICMs).

\begin{tabular}{lcc}
\hline \multirow{2}{*}{ Metal type } & \multicolumn{2}{c}{ Metal content $(\% \mathrm{w} / \mathrm{w})$} \\
\cline { 2 - 3 } & PCBs & GFMBCs \\
\hline $\mathrm{Au}$ & $0.0038 \pm 0.0002$ & $0.0607 \pm 0.0001$ \\
$\mathrm{Cu}$ & $21.4 \pm 0.04$ & $48.3 \pm 0.05$ \\
$\mathrm{Ni}$ & $0.51 \pm 0.003$ & $0.51 \pm 0.001$ \\
\hline
\end{tabular}

Means \pm Standard error.

\section{Fungal dry biomass and changes in culture medium $\mathrm{pH}$}

The amount of dry fungal biomass decreased significantly in the presence of either GFICMs or PCBs; however, this reduction was dependent on the treatment (Figure 4). For instance, $\mathrm{PCBs}$ resulted in stronger growth inhibition for the combination of A. niger MX7 and A. niger MXPE6 when compared to the growth of A. niger MXPE6. However, both fungal treatments showed promising recovery of $\mathrm{Au}$ or $\mathrm{Cu}$ from PCBs, as shown in Figures $3 \mathrm{a}$ and $3 \mathrm{c}$. In contrast, the presence of GFICMs resulted in a similar production of dry biomass in both fungal treatments (Figure 4), though the recovery of $\mathrm{Au}$ or $\mathrm{Cu}$ was limited. Due to the lack of research on the effects of GFICMs or PCBs on fungal growth, we are unable to explain our data.

Regardless the presence of PCBs or GFICMs, the $\mathrm{pH}$ of the A. niger MXPE6 culture media did not show significant variations (4.4 in average) (Figure 5). In contrast, the application of the GFICMs material with A. niger MXPE6 resulted in a significant increase of $\mathrm{pH}$ (6.6) when compared to the control or to the presence of PCBs (4.4 in average). The increase in $\mathrm{pH}$ due to the application of GFICMs agrees with that reported by Brandl et al. (2001), who explained that $A$. niger increases the $\mathrm{pH}$ of the culture medium if the metal concentration in the WEEE is high.

Our data suggest that certain fungal strains may be useful for recovering precious metals from WEEE, as demonstrated for some bacterial strains (Chi et al., 2011). Research on this subject may result in fundamental information for generating low-cost and environmentally sound microbial biotechnologies for the recovery of precious metals from WEEE.

In conclusion, Au tolerance of Aspergillus species could be a good indicator for selecting filamentous fungi able to cause bioleaching of gold from WEEE. Additionally, the use of a fungal consortium, as shown in this study, increases the bioleaching of $\mathrm{Au}$ from PCBs and GFICMs derived from WEEE.
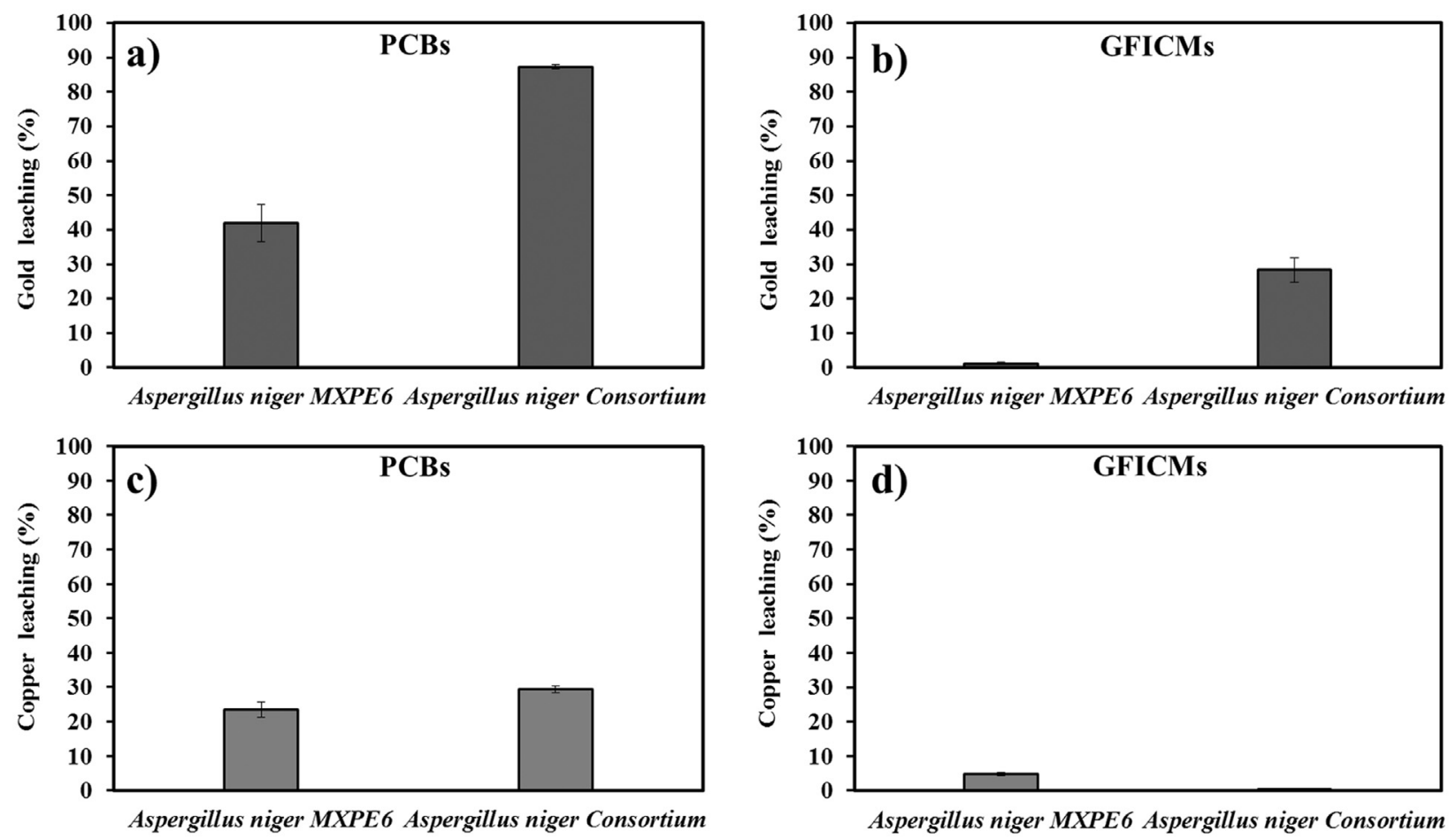

Figure 3 - Gold and copper leaching from electronic waste by an Aspergillus consortium (A. niger MXPE6 + A. niger MX7) and A. niger MXPE6 after 14 days at $28^{\circ} \mathrm{C}$. a) Au-bioleaching from printed circuit boards of cellular phones (PCBs), b) Au-bioleaching at gold-plated finger integrated circuits found in computer motherboards (GFICMs), c) Cu-bioleaching from printed circuit boards of cellular phones, and d) Au-bioleaching at gold-plated finger integrated circuits found in computer motherboards. $\mathrm{n}=3$, Means \pm standard. 


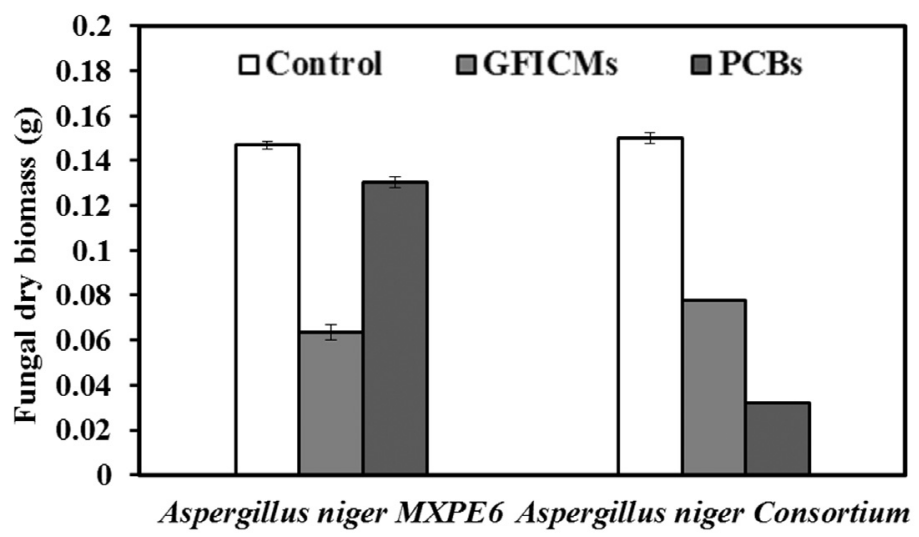

Figure 4 - Dry biomass of the Aspergillus consortium (A. niger MXPE6 + A. niger MX7) and A. niger MXPE6 exposed to printed circuit boards of cellular phones (PCBs) and gold-plated finger integrated circuits found in computer motherboards (GFICMs) after 14 days at $28^{\circ} \mathrm{C}(\mathrm{n}=3$, Means \pm standard error).

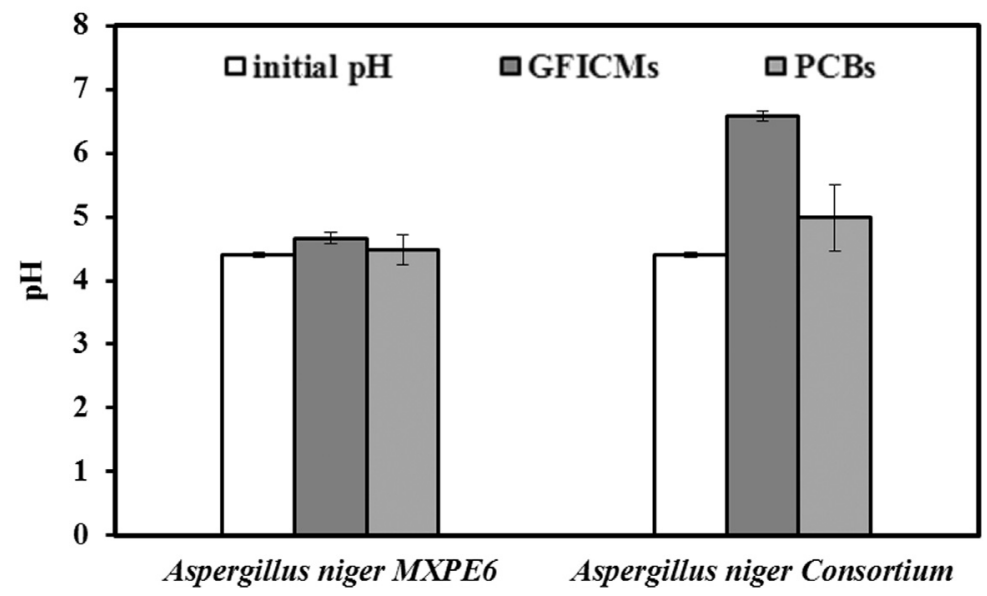

Figure 5 - Variations of $\mathrm{pH}$ induced by the Aspergillus consortium (A. niger MXPE6 + A. niger MX7) and A. niger MXPE6 exposed to printed circuit boards of cellular phones (PCBs) and gold-plated finger integrated circuits found in computer motherboards (GFICMs) after 14 days at $28^{\circ} \mathrm{C}(\mathrm{n}=3$, Means \pm standard error).

\section{Acknowledgments}

This work was financially supported by a CONACYT grant 167176. Special thanks to CONACyT for financial support to J.E.M.A. during his studies.

\section{References}

Biryuzova VI, Korobushkina ED, Pozmogova IN et al. (1987) Accumulation of gold by cell Candida utilis. Mikrobiologiya 56:155-161.

Bosshard P, Bachofen R, Brandl H (1996) Metal leaching of fly ash from municipal waste incineration by Aspergillus niger. Environ Sci Technol 30:3066-3070.

Brandl H, Bosshard R, Wegmann M (2001) Computer-munching microbes: metal leaching from electronic scrap by bacteria and fungi. Hydrometallurgy 59:319-326.
Brandl H, Faramarzi MA (2006) Microbe-metal-interactions for the biotechnological treatment of metal-containing solid waste. China Part 4:93-97.

Chi TD, Lee J, Pandey BD et al. (2011) Bioleaching of gold and copper from waste mobile phone PCBs by using a cyanogenic bacterium. Miner Eng 24:1219-1222.

Choi M, Cho K, Kim D et al. (2004) Microbial recovery of copper from printed circuit boards of waste computer by Acidithiobacillus ferrooxidans. J Environ Sci Heal Part A 39:2973-2982.

Corti CW, Holliday RJ (2004) Commercial aspects of gold applications: From materials science to chemical science. Gold Bull 37:20-26.

Cui J, Zhang L (2008) Metallurgical recovery of metals from electronic waste: A review. J Hazard Mater1 58:228-256.

Gavilán-García A, Román-Moguel A, Almada-Calvo F et al. (2009) Electronic waste generation and technology for an appropriate management in México. Bol Soc Quím Méx 3:85-92. 
He W, Li G, Ma X et al. (2006) WEEE recovery strategies and the WEEE treatment status in China. J Hazard Mater B 136:502-512.

Huang K, Guo J, Xu Z (2009) Recycling of waste printed circuit boards: A review of current technologies and treatment status in China. J Hazard Mater 164:399-408.

Karamushka VI, Gadd GM (1999) Interaction of Saccharomyces cerevisiae with gold: toxicity and accumulation. BioMetals 12:289-294.

Lee J, Song HT, Yoo J (2007) Present status of the recycling of waste electrical and electronic equipment in Korea. Resour Conserv Recy 50:380-397.

Mulligan CN, Galvez-Cloutier R, Renaud N (1999) Biological leaching of copper mine residues by Aspergillus niger. Process Metallurgy 9:453-461.

Mulligan CN, Kamali M (2003) Bioleaching of copper and other metals from low-grade oxidized mining ores by Aspergillus niger. J Chem Technol Biotechnol 78:497-503.

Mulligan CN, Kamali M, Gibbs BF (2004) Bioleaching of heavy metals from a low-grade mining ore using Aspergillus niger. J Hazard Mater 110:77-84.

Osorio-Hernández LW (2009) El níquel, más allá de los límites de la naturaleza. Metal 12:10-13.
Pham VA, Ting YP (2009) Gold bioleaching of electronic waste by cyanogenic bacteria and its enhancement with bio-oxidation. Adv Mater Res 71-73:661-664.

Richardson W (1997) Handbook of Copper Compounds and Applications. Marcel Dekker Inc., New York.

SAS Institute Inc. (2010) The SAS system for windows, ver. 9.0. SAS Institute Inc, Cary, North Carolina.

Singer A, Navrot J, Shapira R (1982) Extraction of aluminum from fly-ash by commercial and microbiologically produced citric acid. Eur J Appl Microbiol Biotechnol 16:228-230.

Sodhi MS, Reimer B (2001). Models for recycling electronics end-of-life products. OR Spektrum 23:97-115.

Sum EYL (1991) The recovery of metals from electronic scrap. Journal of Metallurgy 43:53-61.

Tuncuk A, Stazi V, Akcil A et al. (2012). Aqueous metal recovery techniques from e-scrap: Hydrometallurgy in recycling. Miner Eng 25:28-37.

Vachon P, Tyagi RD, Auclair JC et al. (1994) Chemical and biological leaching of aluminum from red mud. Environ Sci Technol 28:26-30.

Weidenhamer JD, Clement ML (2007) Leaded electronic waste is a possible source material for lead-contaminated jewelry. Chemosphere 7:1111-1115.

Associate Editor: Lara Durães Sette

All the content of the journal, except where otherwise noted, is licensed under a Creative Commons License CC BY-NC. 